\title{
Participatory Dark Sky Quality Monitoring from Italy: Interactions Between Awareness Raising and Research
}

\author{
Andrea Giacomelli1,**, Luciano Massetti², Francesco Sabatini², Elena Maggi ${ }^{3}$ \\ ${ }^{1}$ Attivarti.org, Torniella, Italy \\ ${ }^{2}$ Institute of Biometeorology of the National Research Council of Italy, Florence, Italy \\ ${ }^{3}$ Department of Biology, University of Pisa, Pisa, Italy
}

Received 05 December 2016, Accepted 21 December 2016

\begin{abstract}
Research on light pollution and its effects developed in Italy through a peculiar path. After originating seminal work in the late Nineties, above all the first world atlas of night sky brightness, the academic system apparently did not leverage this asset to a wider set of studies. In parallel, some activities which are prerequisites to research and analysis, such as measurement campaigns or development of calibration tests, were initiated in a "grassroots mode" by other sectors of society, such as non-governmental associations.

One of the relevant example of this process is the BuioMetria Partecipativa project which was started in 2008 in Italy with the aim of encouraging non-professionals to collect data on light pollution as a strategy for environmental awareness raising. The BMP project conjugates this component with a scientific approach, allowing the collection of valuable quantitative environmental data, using a low-cost device, called Sky Quality Meter (SQM), provided to citizens. The measurements are loaded to a database on the project web site, and are published in a variety of formats.

In 2011 the system was extended to collect data from fixed SQM stations for continuous monitoring, with the development of automated data harvesting procedures and leading to complement the citizen science measures with more high-quality time series of light pollution data.

At the national level, the project obtained considerable recognition, in terms of citizen participation and media coverage. Most interestingly from a research perspective, the project acted as a trigger to initiate light pollution studies by Italian experts, namely in the areas of biometeorology and marine ecology.

The article will review the process which led the authors to escalate their operations from awareness raising to research, and will provide an overview of the models and of the first tests conducted in the context of our research studies.
\end{abstract}

Keywords: Italy, Marine ecology, Biometeorology, Citizen science, Awareness raising

\section{Introduction}

Artificial light at night is an essential element of modern civilization, enabling to illuminate residential and industrial areas, and infrastructure after sunset, thus enabling the prolongation of social and economic activities. At the same time, the amount and type of emitted light, often excessive compared to real needs, causes negative effects on various sectors, like professional and amateur astronomic observations, ecology, safety and human health [1-4].

While numerous studies are still underway to quantify the effect of artificial light in the various impact categories above, it is quite clear that over the past decades the introduction of light in nightlife settings has often been done without considering these effects, sometimes even due to the limited knowledge of technicians

\footnotetext{
*Giacomelli A

E-mail address: info@pibinko.org
} 
regarding good design and installation practices. We therefore find ourselves in a situation where there is both the need to investigate the issue related to light pollution and to sensitize various sections of society on this issue.

In this context, Italy seems to hold a peculiar role, since it is historically renowned as one of the countries with the highest level of light pollution [5]. Such a condition is compounded by the fact that, in spite of the remarkable increase in the percentage use of renewable energy (now tending to $40 \%$ of the total energy requirements [6]), the country is strongly dependent on imported fossil fuel sources. This picture should warrant research, knowledge transfer, decision support and awareness raising opportunities to all the stakeholders involved in light pollution issues. However, compared to other countries under similar socio-economic conditions, where an interdisciplinary approach to light pollution studies has developed and is serving various sectors of society, the Italian research system has produced to date a sparse body of knowledge [7-13].

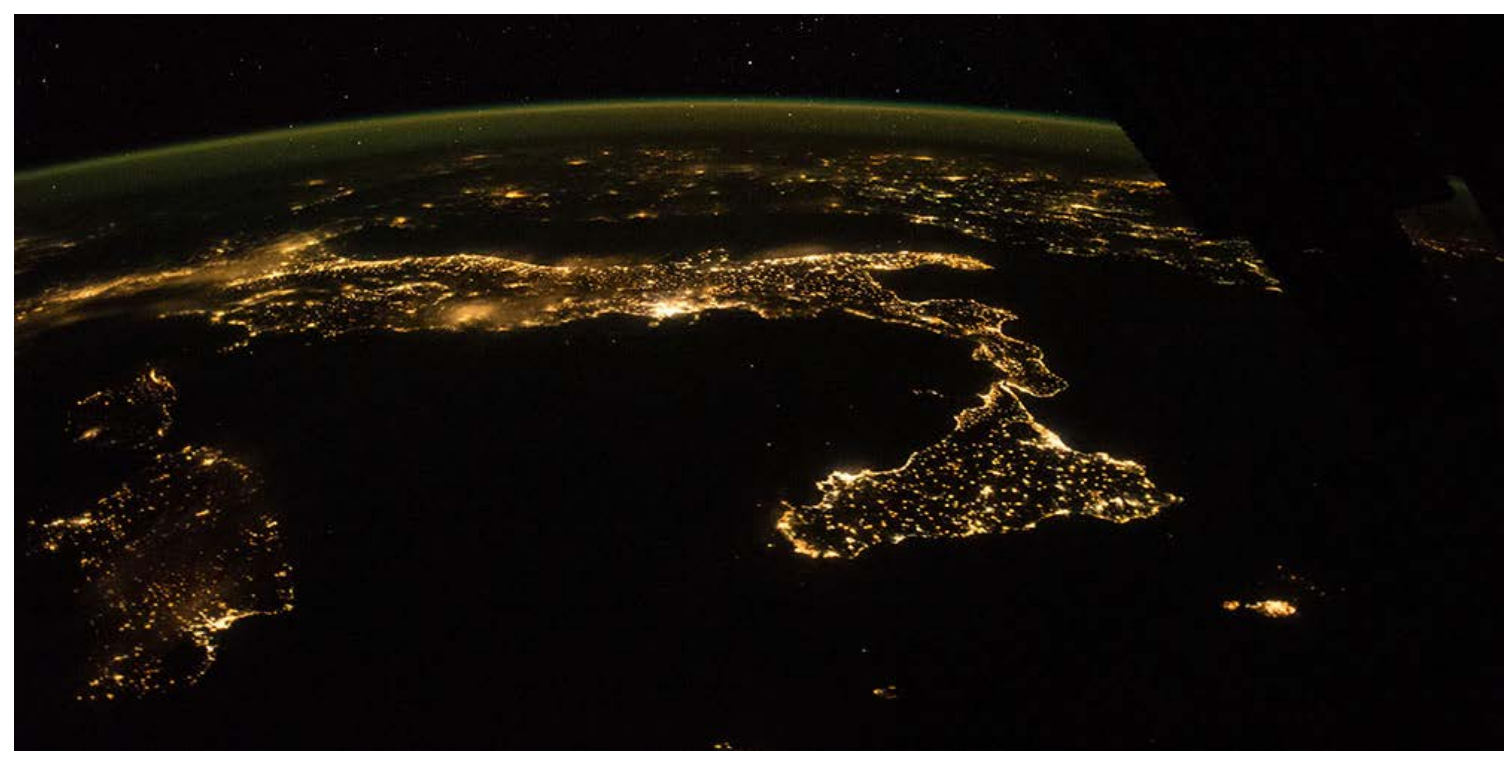

Fig. 1. Italy at night, panorama. ISS Crew Earth Observations Facility and the Earth Science and Remote Sensing Unit, NASA Johnson Space Center; http://eol.jsc.nasa.gov., Image number ISS041-E-90188

These research activities are often fragmented and involving small teams. Consequently, their results are poorly disseminated, both in the academic sector and in other parts of society which may benefit of outreach on the topic of light pollution issues. In this context, actors that have played the role of disseminating this issue to the society, obtained the result of raising awareness of interdisciplinary scientists. This paper deals with one of the experiences that has developed in Italy, describing the Buiometria project and its impacts on scientists working in the areas of biometeorology and marine ecology.

\section{Attivarti.org and the Buiometria Partecipativa Project}

Attivarti.org is a non-profit association created in May 2011. The association's mission is "the protection and the promotion of lesser known resources in the areas of culture, environment, and open innovation”. It was created to give a formal body to a series of initiatives which started in 2006 through the networking of citizens located primarily in Milan and in Southern Tuscany. Attivarti.org is animated on one side by technicians with multiple years of experience in environmental engineering, geographic information systems and land planning, and on the other by residents of three hamlets in Southern Tuscany. The combination of these elements leads to a mode of operation in the development Attivarti.org's initiatives which is possibly not totally new, but still quite original compared to other associations.

The flagship project run by Attivarti.org is called BuioMetria Partecipativa (BMP). This was started in 2008 as an initiative to attain three parallel objectives: raise awareness on light pollution, collect quantitative data to characterize night sky quality, and promote rural areas with dark skies for tourism and educational and research purposes. For the latter purpose, the association has a privileged viewpoint, as its headquarters are in Torniella, a 270-resident village in the Farma Valley (100 km South of Florence), at the centre of one of the three dark areas in Italy.

The BuioMetria Partecipativa working group has been following four main action lines. 
- Citizen science, by engaging people from all sectors of society and age ranges who borrowed Sky Quality Metres (SQM's) [14] from the Attivarti.org pool, or used their own sensor. Figure 2 shows the locations were measurements have been taken between May 2008 and November 2016. The sensors were called "buiometri”, a neologism which in English might become "dark-o-meter" in order to replace the English name of the sensor in interactions with rural stakeholders (hence the name of the project "participatory buiometria”). The collected data is uploaded to the project web site and is subsequently displayed via a web-map interface. A reporting system is also available, allowing the execution of complex queries on the database. Data may also be downloaded and is distributed with an Open Database License.

- Outreach, with over 100 presentations given throughout the country (and occasionally abroad). These presentations were either within events organized directly by the association, invited lectures, or talks submitted at conferences, exhibitions or festivals. The project had a significant presence in the media, with several interviews on national radio stations, one report from one of the main TV channels, and national press. The project has also produced videos, launched a photo contest (in 2010, receiving entries by over 600 participants from 52 countries), created tutorials and more multimedia material. A unique product of the project is a model of a road with a night sky created using $250 \mathrm{~m}$ of optic fiber of three different diameters. The model is equipped with potentiometers controlling the intensity of the street lighting, globes with different levels of transparency, and cut-off covers, thus allowing the simulation of different light pollution issues. The model has been used in various outreach events and hosted in a natural history museum in Leghorn and in Festambiente, one the main national festivals on environmental awareness.

- Networking, by systematically searching for other subjects engaged in the topic of artificial light at night. In this respect the project has established links with numerous stakeholders, activists and researchers, both in Italy and abroad, eventually being invited to participate in the Loss of the Night Network project as the primary point of contact in Italy.

- Monitoring, with the creation of an information system for the acquisition and sharing of night sky brightness data, complementing the hand-held measurements made in citizen science mode. More details about CORDILIT are provided in the following section.

\section{The CORDILIT Network}

In the second half of 2010 the BMP team started to think of a way to implement a network of fixed SQM stations, so as to have a stable set of measurement locations complementing the "bottom up" layer of measures deriving from the citizen science activity. While designing the software to harvest data from the stations, an effort was made to contact all subjects in Italy who were known at the time to be active in this area. This led to a series of workshops meetings in Rome, Nove, and Mantova: the idea of a network of federated sensors took shape. Not all of the contacted organizations accepted to join the group, but still the team had a sufficient number of instruments to move into an operational phase. In March 2011 the CORDILIT (Coordinamento per la Raccolta Dati di Inquinamento Luminoso in Italia, i.e. coordination for the collection of light pollution data in Italy) was launched. The initiative initially comprised five sensors, deriving from the joint operation of VenetoStellato, grouping several amateur astronomer observatories active in light pollution prevention in the Veneto region, and Attivarti.org. As of November 2016, CORDILIT has data from 15 sensors. Plans to add more sensors are being evaluated. As for the BMP hand-held data, the CORDILIT time series are released as raw data under the Open Database License. 


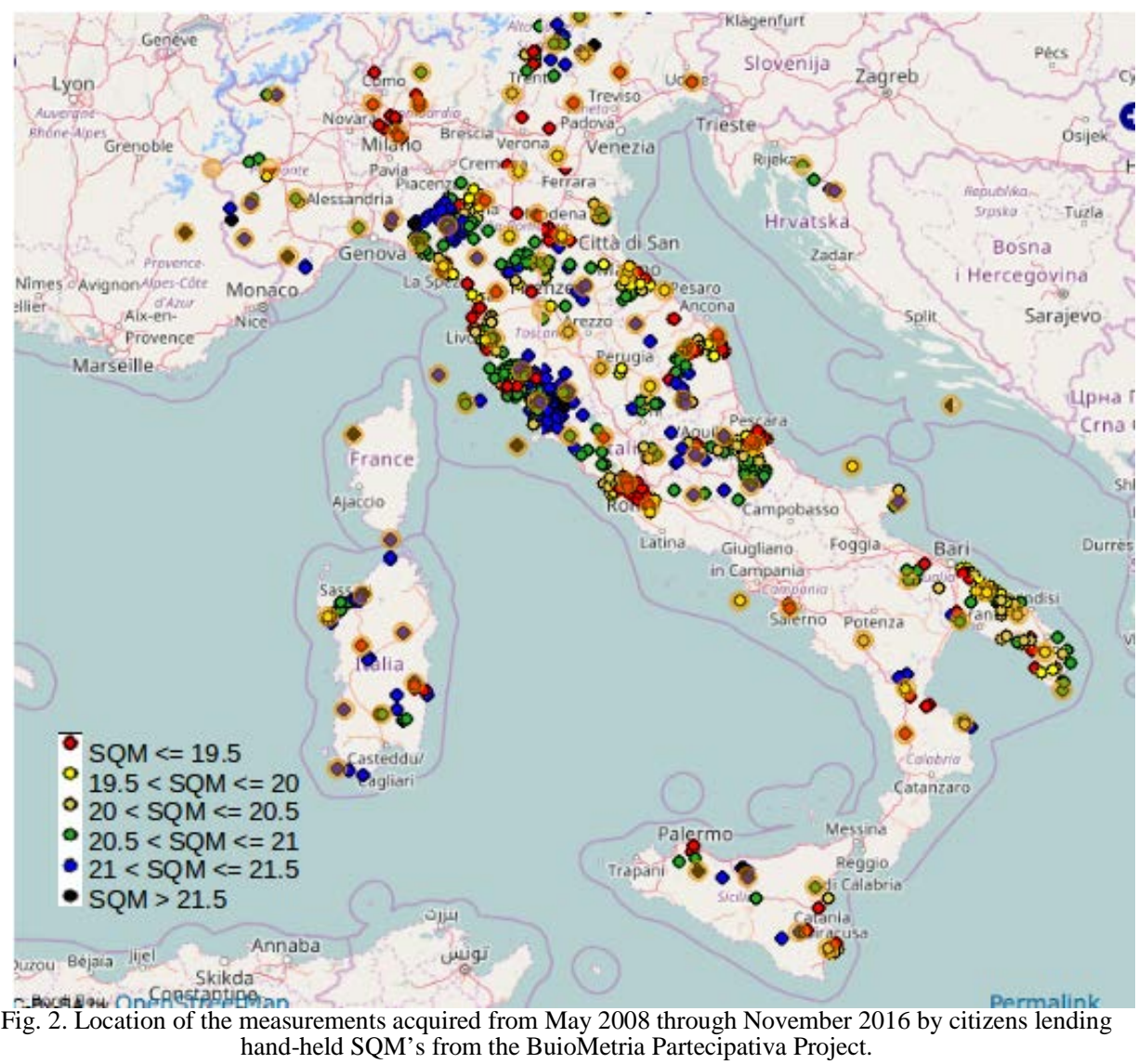

\section{The Role of IBIMET}

In 2014, the Institute of Biometeorology of the National Research Council (hereafter IBIMET) started to collaborate with Attivarti.org.

IBIMET aims to define strategies and develop technological and operational solutions for sustainable agriculture and other environmental issues raised by human activities and climate change.

With the active involvement in the COST Action Loss of the Night Network (LoNNe), IBIMET started to study light pollution and its potential effects on plant physiology.

The first concrete action was made in 2015 when the Attivarti.org and IBIMET organized an inter-comparison campaign in Tuscany. European scientists met to compare sky quality measurements acquired with different devices in Torniella, a dark rural site, and in Florence, a polluted urban site.

The campaign was mainly focused on assessing reliability of low cost SQM devices in comparison to other instruments and the results were published in a final report [15].

Within the COST action, IBIMET and Attivarti.org were also involved in local and national dissemination activities on light pollution, such as participation at public events in Leghorn and Montelupo Fiorentino and publication of a chapter in the book "Anno della Luce", published by the National Research Council during the International Year of Light [16].

After the campaign, IBIMET and Attivarti.org decided to create a fixed network for monitoring dark sky quality in Tuscany, making use of Sky Quality Meters (SQM). In particular, the option was for SQM-LU-DL devices, equipped with shields to protect the sensor from rain. These devices have the advantage of being battery supplied and characterized by storage capacity, as to be used in remote sites that cannot be frequently accessed. After a first comparison in Sesto Fiorentino (Figure 3), one device was installed in the light polluted site at CNR campus and another one in the dark site of Montecristo Island, thanks to the collaboration with the Corpo Forestale dello Stato (Figure 4). 


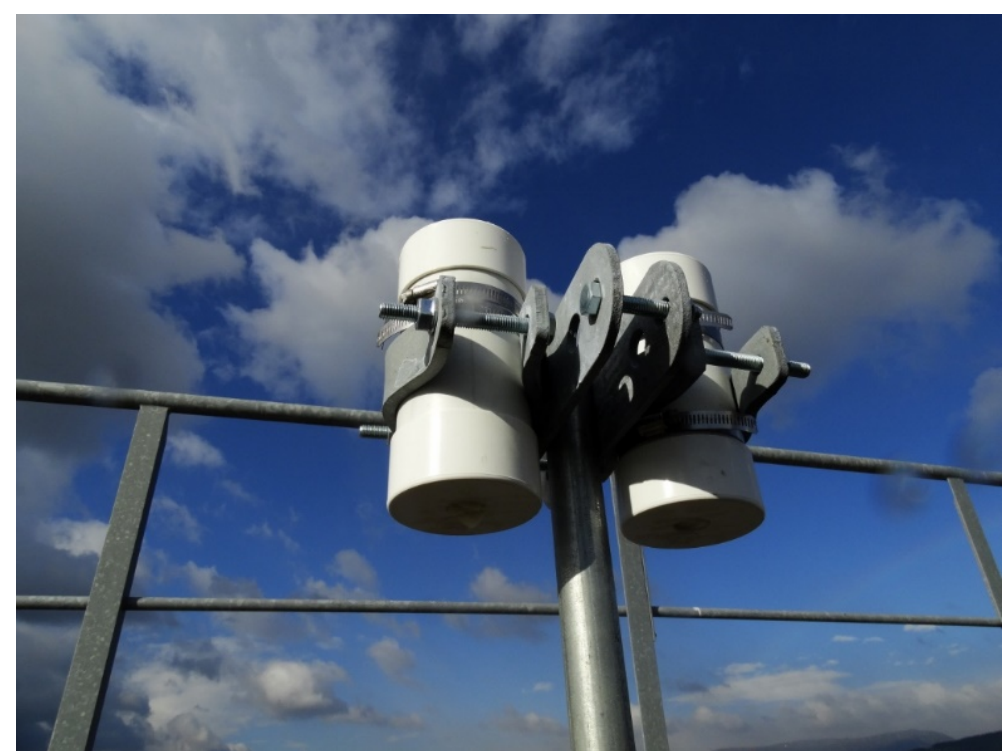

Fig. 3. The SQM sensors at CNR in Sesto Fiorentino. After a cross-calibration phase, one of the two sensors has been re-deployed in Montecristo.

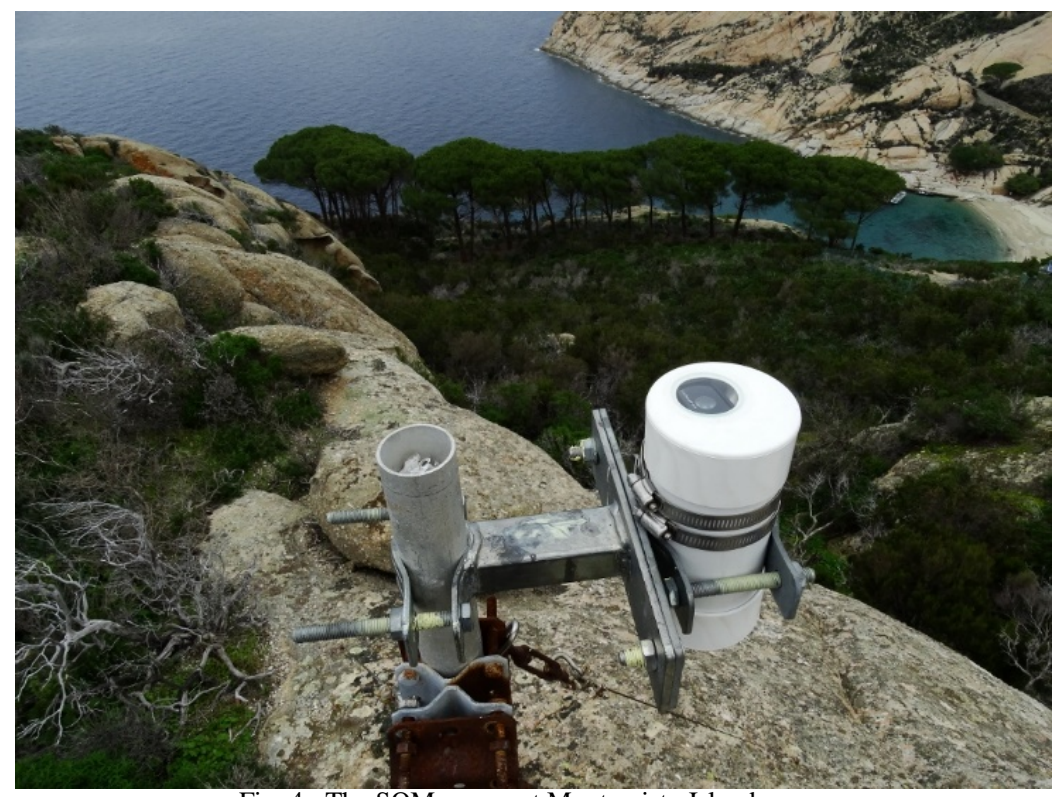

Fig. 4. The SQM sensor at Montecristo Island.

The initial time series of readings allowed a cursory verification of differences in night sky quality at the two sites. Based on a subset of the measurements taken on a clear night without moon and with clear sky in all the region (between Dec. 10 and Dec. 11, 2015, from 5PM to 4AM), Montecristo Island was at 21.42 \pm 0.12 mag/arcsec2 and Sesto CNR at $18.55 \pm 0.19 \mathrm{mag} / \mathrm{arcsec} 2$, so approximately three magnitudes brighter.

The data collected by the IBIMET sensors have been periodically integrated in the CORDLIT database, managed by Attivarti.org.

In the same period, IBIMET also started to investigate potential effects of artificial light at night (ALAN) on plant development and its interaction with other abiotic factors like air temperature. In fact, even though artificial light is used to stimulate plant growth in horticulture, there is a limited knowledge about the effects of artificial street lighting on urban vegetation. Past studies showed some effects of ALAN on plant phenology [17-19], but they were mainly run in a controlled environment. From some observations on Platanus acerifolia, collected at the beginning of winter 2014-2015 in Florence, IBIMET observed that trees under street lighting maintained green 
leaves for a longer time than trees far from the direct light (Figure 5). Taking inspiration from these observations, IBIMET started to systematically monitor autumn phenology of Platanus acerifolia and of other tree species commonly used in the urban environment, in order to assess potential effects of street lighting.

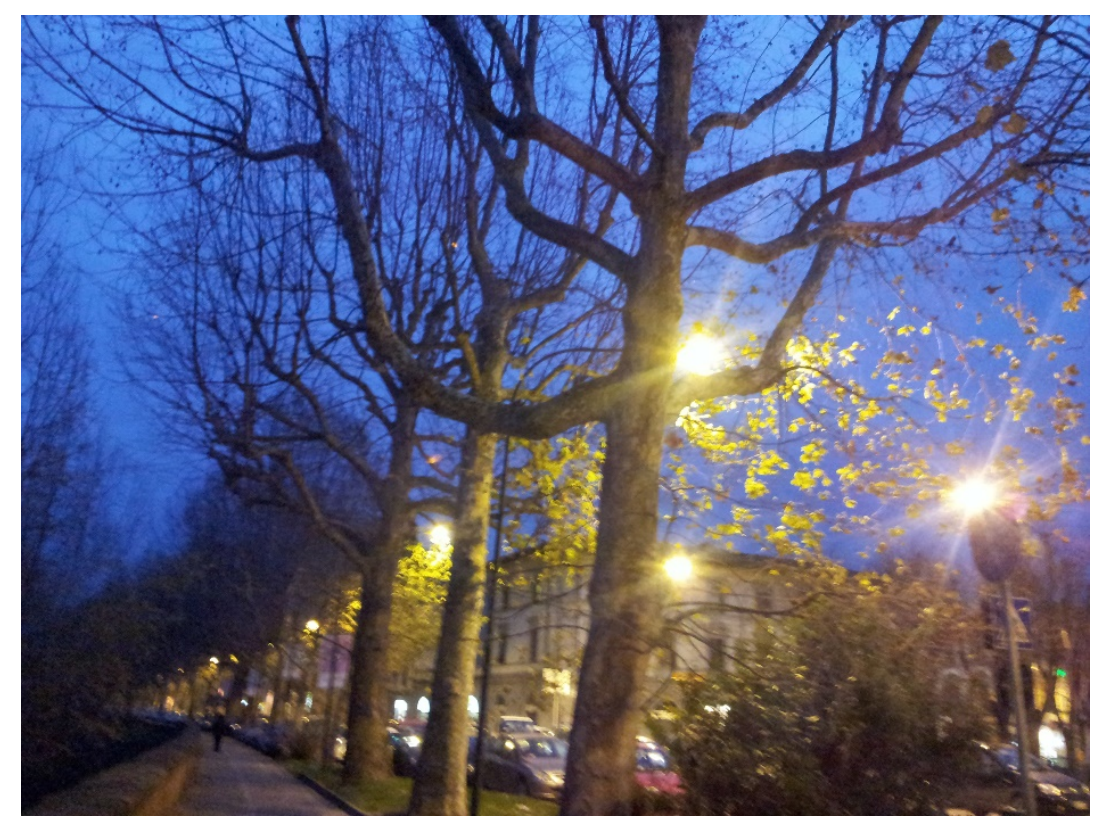

Fig. 5. Platanus acerifolia canopy in the streets of Florence (7th January 2015)

\section{Collaborative Activities with UNIPI}

In 2015, Attivarti.org and the Department of Biology of the University of Pisa (hereafter UNIPI) started a collaborative experience, with the aim of studying possible effects of night light pollution on marine coastal assemblages. The research activities of marine ecologists at UNIPI focus on the role of a variety of factors in structuring coastal assemblages, from climate change to biological invasions, from loss of biodiversity to local anthropogenic sources of stress. Coastal habitats are, in fact, threatened by a variety of stressors, directly or indirectly related to human activities. A recent review by Davies and colleagues [20] showed that artificial light pollution is globally widespread in marine environments; coastal habitats, in particular, are exposed to high levels of artificial light at night, due to permanent urban developments (e.g. cities, towns and their harbors), as well as to temporary sources of light linked to shipping and fisheries activities.

Light pollution has the potential to alter many biological processes, due to the key role of light intensity and photoperiod for organismal metabolism and behavior. Research on terrestrial systems has shown that light pollution may cause habitat displacement, modulate reproductive development, alter daily activity patterns, disrupt navigations [21-24] . Recent studies made important advances on potential effects on freshwater systems [25-27]. However, knowledge of the effects of light pollution on many aquatic habitats is still scarce. In particular, only a few studies experimentally investigated possible effects on marine coastal environments [28-29]. This is at odds with the key role of light in guiding different metabolic processes (e.g. photosynthesis) and behaviors (e.g. synchronized broadcast spawning events, vertical migrations, prey location, bioluminescent communications) in marine species.

Marine ecologists of UNIPI, in collaboration with Attivarti.org, decided to focus attention on the possible role of night light pollution as an additional key stressor in structuring coastal benthic habitats. In fact, by living at the interface between the aerial and the marine kingdom, intertidal assemblages represent potentially highly impacted systems from alteration of night light intensity and spectra. This is of major importance, considering the high productivity of these systems. The aim of the collaboration was twofold: first, to extend the BuioMetria partecipativa database, by starting a monitoring activity specifically focused on intertidal sites. This activity was carried out with the use of portable SQM devices from Attivarti.org. Second, to run manipulative in situ 
investigations, to experimentally test the potential role of night light pollution on small food webs. This kind of experiments imply finding a suitable, relatively dark location where to artificially lit replicated sites, while leaving untouched others (i.e. additional replicated sites are left dark at night and used as controls), in order to correctly disentangle the possible effect of artificial light at night treatment from natural variability among different sites. Due to the current transition from high-pressure sodium (HPS) to light-emitting diode (LED) lighting [5], UNIPI opted for using white LED lamps to simulate the installation of sources of artificial light along the coast. For these filed investigations, we were hosted by the Marina Militare of La Spezia at Maralunga (Liguria region), where intertidal rocky shore food webs are currently investigated at each of two lit and 2 control sites (Fig. 6), and nighttime brightness is sampled by means of SQMs.

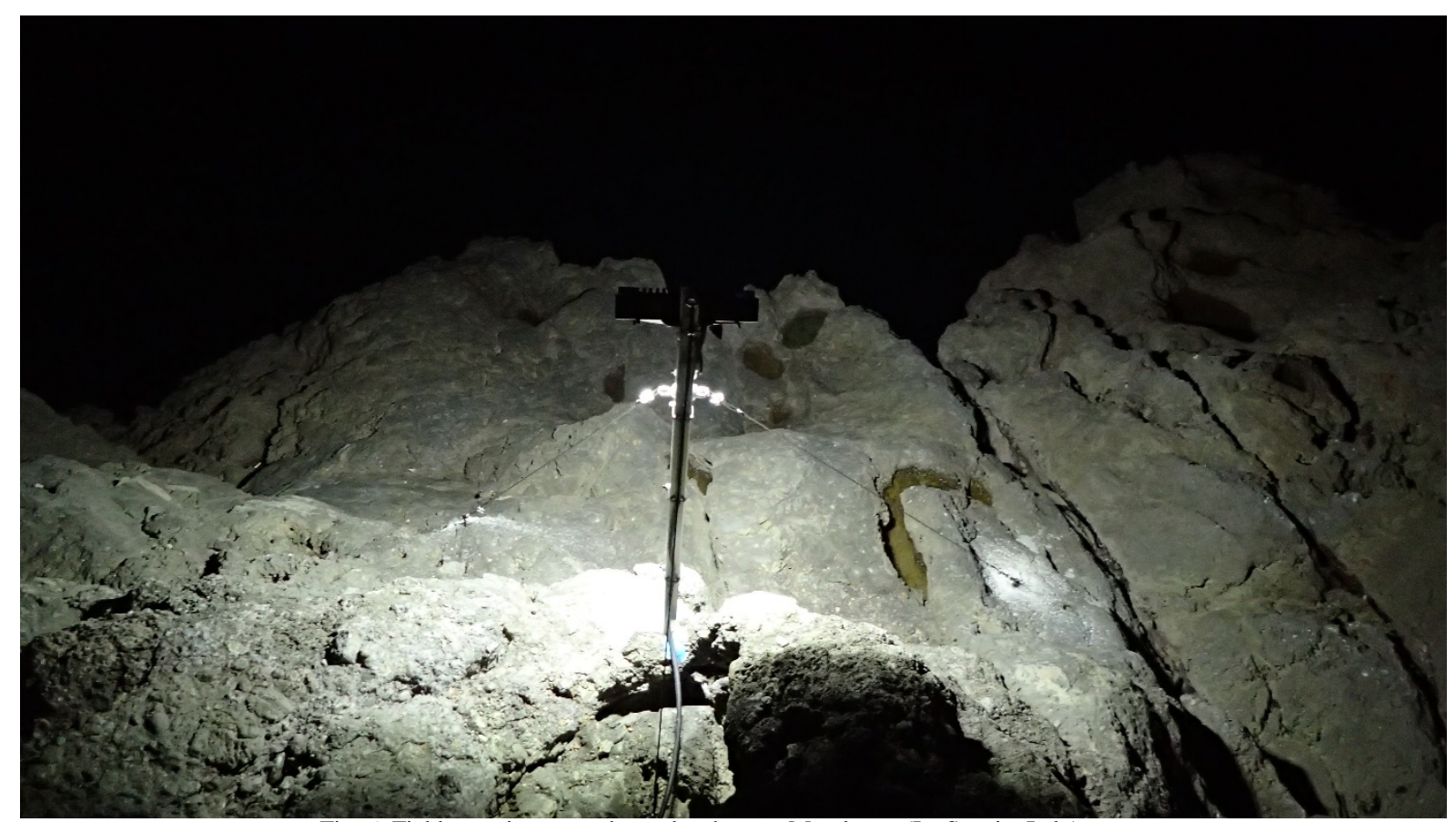

Fig. 6. Field experiment on the rocky shore at Maralunga (La Spezia, Italy).

\section{Conclusions}

Interdisciplinary research in the area of artificial light at night is a topic that in Italy followed a peculiar path. After a phase at the end of the Nineties, which spawned seminal works such as the first light pollution world atlas [30], the potential that may have derived from such works has not been exploited at the national level by research institutions. This is at odds with the high levels of light pollution characterizing the Italian peninsula and the consequent potential interest of Italian scientists on the topic.

The topic has been indeed maintained alive by other organizations, often operating more on the outreach and activism sectors, starting from initiatives aimed at raising awareness on the topic of light pollution, collecting field data, and campaigning to support the introduction of adequate light pollution mitigation guidelines in regional legislation.

These efforts have served as one of the enabling factors to trigger new research work, which has started to account for the interdisciplinary approach that in other countries has produced relevant results. Scientific investigations on the effects of artificial light at night on plants and coastal benthic habitats in Italy are still in progress and conclusions cannot yet be made. However, the efforts made to date are relevant to show the consolidation of a 'knowledge system' related to ALAN studies that shows a maturation of the potential to investigate ALAN issues with an interdisciplinary approach, and is expected to foster results in the short term. In parallel, the "bottom up" awareness raising action by the BuioMetria Partecipativa project is expected to continue at least through June 2018, which will mark ten years of this initiative, trusting that it will inspire Italian and international scientists to develop more research activities in Italy as a case study, and enhancing the mode of operation which led to the collaborations summarized in this article. 


\section{Acknowledgements}

Acknowledgments for this work go to: Francesco Giubbilini, Luca Delucchi, and Stefano Costa for their support in the early stages (2008-2012) of the BuioMetria Partecipativa and CORDILIT projects, Leopoldo Dalla Gassa and the Veneto Stellato Association, for their ongoing support in the CORDILIT operation, the ES-1204 Loss of the Night Network Cost Action, and to the communities of Torniella and Piloni, in Southern Tuscany for their support in the 2015 LoNNe intercomparison campaign and most of all for their continued commitment in the BuioMetria Partecipativa Project and other Attivarti.org initiatives.

\section{References}

[1]Aubé, M., Roby, J., \& Kocifaj, M. (2013). Evaluating potential spectral impacts of various artificial lights on melatonin suppression, photosynthesis, and star visibility. PloS one, 8(7), e67798.

[2] Gaston, K. J., Visser, M. E., \& Hölker, F. (2015). The biological impacts of artificial light at night: the research challenge.

[3] Marchant, P. R. (2004). A demonstration that the claim that brighter lighting reduces crime is unfounded. British Journal of Criminology, 44(3), 441-447.

[4] Reiter, R. J., Tan, D. X., Korkmaz, A., Erren, T. C., Piekarski, C., Tamura, H., \& Manchester, L. C. (2007). Light at night, chronodisruption, melatonin suppression, and cancer risk: a review. Critical Reviews ${ }^{\mathrm{TM}}$ in Oncogenesis, 13(4).

[5] Falchi, F., Cinzano, P., Duriscoe, D., Kyba, C. C., Elvidge, C. D., Baugh, K., ... \& Furgoni, R. (2016). The new world atlas of artificial night sky brightness. Science advances, 2(6), e1600377.

[6] Gestore Servizi Energetici. (2015). Energia da fonti rinnovabili in Italia. Dati preliminari 2015. available at: http://www.gse.it/it/Statistiche/RapportiStatistici/Pagine/default.aspx, February 2016

[7] Marcantonio, M., Pareeth, S., Rocchini, D., Metz, M., Garzon-Lopez, C. X., \& Neteler, M. (2015). The integration of Artificial Night-Time Lights in landscape ecology: A remote sensing approach. Ecological Complexity, 22, 109-120.

[8] Nesci, R. (2014) Quante stelle vedi dal tuo balcone? Le Stelle n.136. 64-71.

[9] Priori, P., Scaravelli, D. (2015). Move under light or shade: habitat use and lightings in different Mediterranean bat species. In: 4th International Berlin Bat Meeting: Movement Ecology of Bats. Leibniz Institute for Zoo and Wildlife Research (IZW), Berlin.

[10] Ceola, S., Laio, F., \& Montanari, A. (2014). Satellite nighttime lights reveal increasing human exposure to floods worldwide. Geophysical Research Letters, 41(20), 7184-7190.

[11] Giacomelli, A., Falchi, F., Dalla Gassa, L., Di Sora, M., Massetti, L. (2015). Artificial Light at Night in Italy: a joint perspective by four NGOs. In Proceedings of the Balkan Light 2015, Athens. 69-72.

[12] Giacomelli, A., Ceccarini, G. (2015). Atti della conferenza Innovation in environmental education: ICT and intergenerational learning, Firenze. Integrating Culture, Environment, and Open Innovation for Awareness Raising: a case from the Farma Valley, Tuscany.

[13] Giubbilini, F., Giacomelli, A. (2010). Gazzetta Ambiente n.3. Visioni globali e azioni locali sull'inquinamento luminoso.

[14] Kyba, C. C., Tong, K. P., Bennie, J., Birriel, I., Cool, A., Danielsen, A., Davies, T.W., den Outer, P., Edwards, W., Ehlert, R., Falchi, F., Fischer, J., Giacomelli, A., Giubbilini, F., Haaima, M., Hesse, C., Heygster, G., Hoelker, F., Inger, R., Jensen, L.J., Kuechly, H.U., Kuehn, J., Langill, P., Lolkema, D.E., Nagy, M., Nievas, M., Ochi, N., Popow, E., Posch, T., Puschnig, J., Ruhtz, T., Schmidt, W., Schwarz, R., Schwope, A., Spoelstra, H., Tekatch, A., Trueblood, M., Walker, C.E., Weber, M., Welch, D.L., Zamorano, J., Gaston, K.J. (2015). Worldwide variations in artificial skyglow. Scientific reports, 5, 8409.

[15] Kyba, C., Bouroussis, C., Canal, R., Falchi, F., Giacomelli, A., Haenel, A., Kolláth, Z., Massetti, L., Ribas, S., Spoelstra, H., Tong, K.P., Wuchterl, G. Report of the 2015 Intercomparison report. Accessed 25th November 2016. http://www.cost-lonne.eu/wp-content/uploads/2015/04/2015_LoNNe_IC_Report.pdf

[16] Massetti, L., Sabatini, F., Giacomelli, A. (2016). Il buio e la luce artificiale. Inn: Mugnai D. (eds) Anno della luce. 11-23.

[17] Cathey, H. M., \& Campbell, L. E. (1975). Effectiveness of five vision-lighting sources on photo-regulation of 22 species of ornamental plants. Journal-American Society for Horticultural Science (USA).

[18] Gaston, K. J., Visser, M. E., \& Hölker, F. (2015). The biological impacts of artificial light at night: the research challenge.

[19] Kramer, P. J. (1937). Photoperiodic stimulation of growth by artificial light as a cause of winter killing. Plant physiology, 12(3), 881.

[20] Davies, T. W., Duffy, J. P., Bennie, J., \& Gaston, K. J. (2014). The nature, extent, and ecological implications of marine light pollution. Frontiers in Ecology and the Environment, 12(6), 347-355.

[21] Kempenaers, B., Borgström, P., Loës, P., Schlicht, E., \& Valcu, M. (2010). Artificial night lighting affects dawn song, extra-pair siring success, and lay date in songbirds. Current Biology, 20(19), 1735-1739.

[22] Davies, T. W., Bennie, J., \& Gaston, K. J. (2012). Street lighting changes the composition of invertebrate communities. Biology letters, rsbl20120216.

[23] Dominoni, D., Quetting, M., \& Partecke, J. (2013). Artificial light at night advances avian reproductive physiology. Proceedings of the Royal Society of London B: Biological Sciences, 280(1756), 20123017. 
[24] Spoelstra, K., van Grunsven, R. H., Donners, M., Gienapp, P., Huigens, M. E., Slaterus, R., ... \& Veenendaal, E. (2015). Experimental illumination of natural habitat - an experimental set-up to assess the direct and indirect ecological consequences of artificial light of different spectral composition. Phil. Trans. R. Soc. B, 370(1667), 20140129.

[25] Poulin, C., Bruyant, F., Laprise, M. H., Cockshutt, A. M., Vandenhecke, J. M. R., \& Huot, Y. (2013). The impact of light pollution on diel changes in the photophysiology of Microcystis aeruginosa. Journal of plankton research, fbt088.

[26] Brüning, A., Hölker, F., Franke, S., Kleiner, W., \& Kloas, W. (2016). Impact of different colours of artificial light at night on melatonin rhythm and gene expression of gonadotropins in European perch. Science of the Total Environment, 543, 214-222.

[27] Hölker, F., Wurzbacher, C., Weißenborn, C., Monaghan, M. T., Holzhauer, S. I., \& Premke, K. (2015). Microbial diversity and community respiration in freshwater sediments influenced by artificial light at night. Phil. Trans. R. Soc. B, 370(1667), 20140130.

[28] Davies, T. W., Coleman, M., Griffith, K. M., \& Jenkins, S. R. (2015). Night-time lighting alters the composition of marine epifaunal communities. Biology letters, 11(4), 20150080.

[29] Navarro-Barranco, C., \& Hughes, L. E. (2015). Effects of light pollution on the emergent fauna of shallow marine ecosystems: Amphipods as a case study. Marine pollution bulletin, 94(1), 235-240.

[30] Cinzano, P., Falchi, F., \& Elvidge, C. D. (2001). The first world atlas of the artificial night sky brightness. Monthly Notices of the Royal Astronomical Society, 328(3), 689-707. 